Available online at GSC Online Press Directory

GSC Advanced Research and Reviews e-ISSN: 2582-4597, CODEN (USA): GARRC2

Journal homepage: https://www.gsconlinepress.com/journals/gscarr

(RESEARCH ARTICLE)

\title{
NSAIDs and opioids antinociception in a thermal murine phasic pain
}

\author{
Miranda Hugo F 1, ${ }^{*}$, Noriega Viviana ${ }^{2}$, Sierralta Fernando ${ }^{3}$, Sotomayor-Zárate Ramón ${ }^{4}$ and Prieto Juan \\ Carlos 2,3 \\ ${ }^{1}$ Neuroscience Departament, Faculty of Medicine, Universidad de Chile, Santiago, Chile. \\ ${ }^{2}$ Cardiovascular Department; Clinical Hospital, Universidad de Chile, Santiago, Chile. \\ ${ }^{3}$ Pharmacology Program, ICBM, Faculty of Medicine, Universidad de Chile, Santiago, Chile. \\ ${ }^{4}$ Laboratorio de Neuroquímica y Neurofarmacología, Centro de Neurobiología y Fisiopatología Integrativa, Instituto de \\ Fisiología,Facultad de Ciencias, Universidad de Valparaíso. Chile.
}

Publication history: Received on 24 March 2020; revised on 28 March 2020; accepted on 29 March 2020

Article DOI: https://doi.org/10.30574/gscarr.2020.2.3.0022

\begin{abstract}
Pain is an unpleasant sensation that causes mild or severe physical discomfort, by which induces the use of analgesics which are basically of two types: opioids or NSAIDs. The objectives of the present study was to evaluate the antinociception activity induced by NSAIDs and opioids in a thermal model of animal pain, the tail flick assay, and to determine the effect of the MOR antagonist, naltrexone. Antinociception was assessed by the tail flick test using an digital algesiometer. The rank orden of potency was fentanyl $>$ morphine $>$ ibuprofen $>$ tramadol $>$ codeine $>$ meloxicam $>$ paracetamol and the antinociceptive ratio, compared with paracetamol, was between 460 for fentanyl and 1 for meloxicam. Pretreatment with the opioid receptor antagonist, naltrexone, $1 \mathrm{mg} / \mathrm{kg}$ i.p., significant reversed the antinociceptive effect of NSAIDs and opioids. The results obtained with naltrexone in this assay confirm the antagonism of this agent on opioids. However, the antagonism over NSAIDs is a new finding since that has not been previously reported. This study test that NSAIDs and opioids induce antinociceptive activity in a thermal murine phasic pain with the following rank orden of potency fentanyl $>$ morphine $>$ ibuprofen $>$ tramadol $>$ codeine $>$ meloxicam $>$ paracetamol. Although the mechanisms of action of these drugs are different, naltrexone, a MOR antagonist, blocked the effects of both agents, suggesting that inhibition of pain seem partially mediated by MOR with association to central mechanisms.
\end{abstract}

Keywords: Antinociception; Naltrexone; Opoids; NSAIDs; Tail flick

\section{Introduction}

Pain is an unpleasant sensation that causes mild or severe physical discomfort, by which induces the use of analgesics, these agents are basically of two types: opioids or NSAIDs. Furthermore, there are different models of animals to assess pain, among which is the tail flick, one of the oldest nociceptive test [1]. In this phasic pain model, the tail is exposing to a controlled infrared heat beam and the measured parameter is the latency, in seconds, for tail flick reflex following tail exposure to a heat stimulus. The tail flick is a spinal reflex, but it is subject to supraspinal influences that can affect this reflex [2].

NSAIDs are drugs widely used in the treatment of pain and inflammation. The main mechanism assigned to these drugs is the inhibition of cyclooxygenase enzymes (COXs), compromised in the biosynthesis of prostaglandins (PGs) and thromboxanes (TXs). These agents are important mediators in the processes of pain, inflammation and fever. 3 isoforms of COXs are recognized: COX-1, COX-2 and COX-3, with peculiar characteristics each. Thus, COX-1 is found in platelets, stomach, blood vessels, kidney and other tissues. COX-2 is found in inflamed tissues and other tissues such as kidney. COX-3 is expressed in spinal cord, cerebral cortex, endothelial cells, monocytes and heart. Various evidences have shown

\footnotetext{
* Corresponding author: Miranda Hugo F
}

Copyright (C) 2020 Author(s) retain the copyright of this article. This article is published under the terms of the Creative Commons Attribution Liscense 4.0. 
that NSAIDs in addition to their inhibitory effect on COXs there are other mechanisms that help explain the actions of NSAIDs. These include interactions with nitric oxide, cholinergic, monoaminergic, serotonergic, endocannabinoid and others systems at molecular level [3 - 5].

The effectiveness of opioids in relieving pain has been proven in several clinical and animal trials. Opioid-induced analgesia is due to the activation of receptors located in the central and peripheral nervous system. Currently, five types of opioid receptors have been described: mu receptor (MOR), kappa receptor (KOR), delta receptor (DOR), nociception receptor (NOR) and zeta receptor (ZOR). Within these different types, the following subtypes are described: mu1, mu2, mu3, kappa1, kappa2, kappa3, delta1 and delta2 [6]. Each of the different opioid receptors have been confirmed by studies of their crystalline structures derived with the use of antagonists [7]. Very different roles have been assigned to different receptor subtypes, so the mu-1 receptor is responsible for analgesia and dependence, the mu- 2 receptor is responsible for euphoria, dependence, respiratory depression, miosis, constipation and the mu-3 receptor induces vasodilation. KOR receptors play a part in analgesia, diuresis and dysphoria. DOR receptors have a role in analgesia and the reduction of gastric motility. NOR receptors cause analgesia and hyperalgesia, depending on the concentration and ZOR receptors regulate the development of normal and tumorigenic cells and tissues [8].

The study of antinociceptive activity of NSAIDs and opioids has been recognized in animal and clinical studies, nevertheless comparative readings of such drugs in animal pain methods are few. On the other hand, the effect of MOR opioids antagonists in the antinociception induced by NSAIDs and opioids are still less. The objectives of the present study was to evaluate the antinociception activity induced by NSAIDs and opioids in a thermal model of animal pain, the tail flick assay, and to determine the effect of the MOR antagonist, naltrexone.

\section{Material and methods}

\subsection{Animals}

Male CF-1 mice (28-30 g), were used and housed on a $12 \mathrm{~h}$ light-dark cycle at $22^{\circ} \pm 2^{\circ} \mathrm{C}$ with access to food and water ad libitum. Experiments were performed in accordance with current Guidelines for The Care of Laboratory Animals and Ethical Guidelines for investigation of experimental pain approved by the Animal Care and Use Committee of the Faculty of Medicine, University of Chile. Animals were acclimatized to the laboratory for at least $1 \mathrm{~h}$ before testing, used only once in the protocol and were euthanized by intraperitoneal (i.p.) injection of $60 \mathrm{mg} / \mathrm{kg}$ of pentobarbital. In each protocol was used a minimum mice (6-8) to reach definitive results of the drug treatments.

\subsection{Nociceptive test}

Antinociception was assessed by the tail flick test as previously described [9], using an digital algesiometer (U. Basile, Comerio, Italy). The animal withdraws its tail in response to the heat applied, the reaction time of this movement is known as tail flick latency. A prolongation of the reaction time is accepted as antinociceptive activity. A cut-off time of 8 seconds was set as the threshold to avoid damage to the tail of the animal. Control reaction time (latency of the response) was recorded twice, with an interval of $10 \mathrm{~min}$ between readings. Only animals with baseline reaction times between 2 and $3 \mathrm{~s}$ were used in the experiments. For each mouse the tail flick latency was recorded prior to drug administration (control latency or baseline value) and at 30 minutes after i.p. drug administration. The antinociceptive response was calculated as percent of maximum possible effect (\% MPE), where \% MPE $=[($ test - control $) /(8-$ control $)] \times$ 100. Groups of six to eight animals were used for each dose and for each treatment.

\subsection{Protocol}

Dose response curves, i.p. for fentanyl (0.003-0.100mg/kg), morphine (1-30 mg/kg), tramadol (1-30 mg/kg), codeine (1-30 mg/kg), ibuprofen (1-30 mg/kg), meloxicam (1-30 mg/kg) and paracetamol $(10-600 \mathrm{mg} / \mathrm{kg})$ were obtained using at least six animals at each of at least four doses. A squares linear regression analysis of the log dose response curve allowed the calculation of the doses that produced $25 \%$ of antinociception when each drug was administered alone (ED25). ED25 was used in the tail flick test as the equieffective dose for each NSAIDs or opioids before and after i.p. administration of $1 \mathrm{mg} / \mathrm{kg}$ of naltrexone, dose from previously published studies [9].

\subsection{Drugs}

The drugs were freshly dissolved in a physiological salt solution of $10 \mathrm{mg} / \mathrm{kg}$ for i.p. administration. Ibuprofen by Laboratory Chile and meloxicam by Saval Laboratories Chile, Naltrexone hydrochloride, morphine hydrochloride, c odeine phosphate, fentanyl hydrochloride and tramadol hydrochloride were purchased from Sigma-Aldrich Chemical Co, St.- Louis, MO, USA. 


\subsection{Statistical analysis}

Results are presented as means \pm SEM. Statistical difference between before and after the treatment with naltrexone was assessed by Student's test for independent means and p values less than $0.05(\mathrm{p}<0.05)$ were considered statistically significant. Statistical analyses were performed using the program Pharm Tools Pro, version 1.27, McCary Group Inc., PA, USA.

\section{Results}

\subsection{Antinociception induced by NSAIDs and opioids in the tail flick assay}

The i.p. administration in the tail flick test, of the following NSAIDs: ibuprofen, meloxicam or paracetamol produced a dose-related antinociception accompanied by an increase the control time latency with an ED $25 \mathrm{of} 1.81 \pm 0.37 \mathrm{mg} / \mathrm{kg}$, $12.33 \pm 1.92$, and $35.40 \pm 3.92$ respectively. In addition, the i.p. administration in the tail flick assay, of the following opioids: fentanyl, morphine, tramadol or codeine increase the control latency time with an ED 25 of $0.077 \pm 0.01,1.31 \pm$ $0.54,2.46 \pm 0.15$ and $11.85 \pm 0.90$, respectively. All these results are shown in table 1 and figure 1 . The rank orden of potency of the mice latency time, demonstrated by the $\mathrm{ED}_{25}$, was the following: fentanyl > morphine $>$ ibuprofen $>$ tramadol $>$ codeine $>$ meloxicam $>$ paracetamol, see table 1 . The antinociceptive ratio, compared with paracetamol, was between 460 for fentanyl and 1 for meloxicam, as shown in table 1.

Table $1 \mathrm{ED}_{25}$ values with SEM in $\mathrm{mg} / \mathrm{kg}$, for the antinociceptive activity of opioids and NSAIDs, administered i.p., in the tail flick assay of mice

\begin{tabular}{lll}
\hline \multicolumn{1}{c}{ Drug } & ED $_{25} \pm$ SEM $(\mathbf{m g} / \mathbf{k g})$ & Antinociceptive ratioa \\
\hline Fentanyl & $0.077 \pm 0.01$ & 460 \\
Morphine & $1.31 \pm 0.54$ & 27 \\
Ibuprofen & $1.81 \pm 0.37$ & 19 \\
Tramadol & $2.46 \pm 0.15$ & 14 \\
Codeine & $11.85 \pm 0.90$ & 3 \\
Meloxicam & $12.33 \pm 1.92$ & 3 \\
Paracetamol & $35.40 \pm 3.92$ & 1 \\
\hline
\end{tabular}

\subsection{Effect of naltrexone on antinociception of NSAIDs and opioids}

The pretreatment of mice with $1 \mathrm{mg} / \mathrm{kg}$ of naltrexone i.p., dose which does not induce change in the basal antinociception or spontaneous behavior of the tail flick mice. Table 2 show that pretreatment with the opioid receptor antagonist, naltrexone, $1 \mathrm{mg} / \mathrm{kg}$ i.p., significant reversed the antinociceptive effect of fentanyl, morphine, ibuprofen, tramadol, codeine and meloxicam. The effect of naltrexone is demonstrated in an increased the $\mathrm{ED}_{25}$ values of latency time of NSAIDs and opioids. The ratio of change of the ED25 values was 1.29 for fentanyl, 1.94 for morphine, 2.07 for ibuprofen, 2.17 for tramadol, 2.54 for codeine, 2.90 for meloxicam and 3.11 for paracetamol. 

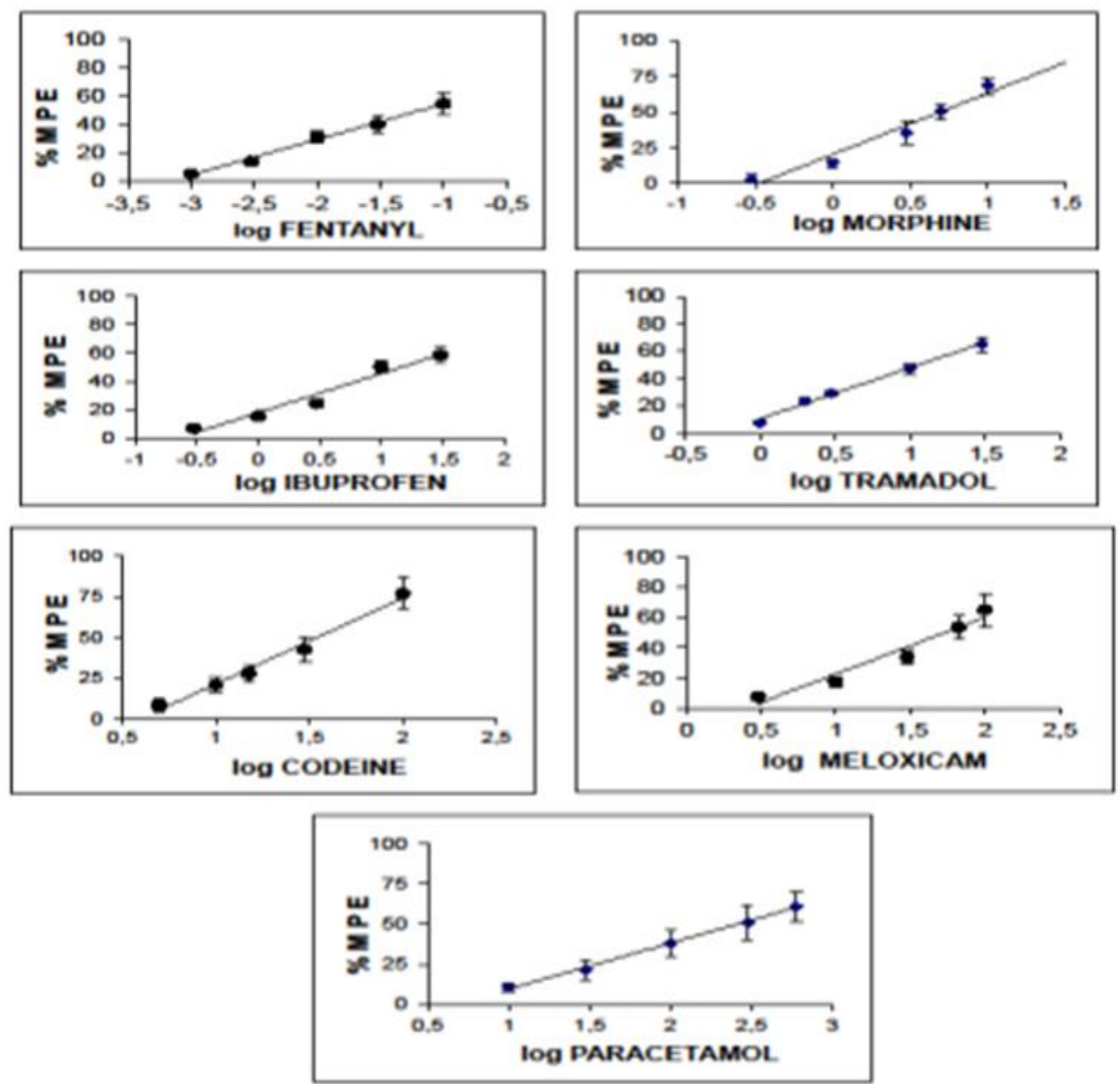

Figure 1 Dose-response curves for the antinociceptive activity induced by fentanyl, morphine, ibuprofen, tramadol, codeine, meloxicam and parcetamol in the tail flick test of mice. Each point is the mean with SEM of 6-8 mice. \% MPE represented as percent of maximum possible effect.

Table 2 Effect of $1 \mathrm{mg} / \mathrm{kg}$ i.p. of naltrexone on the $\mathrm{ED}_{25}$ values with SEM in $\mathrm{mg} / \mathrm{kg}$, for the antinociceptive activity of opioids and NSAIDs, administered i.p., in the tail flick assay of mice.

\begin{tabular}{llcl}
\hline Drug & $\begin{array}{l}\text { Before naltrexone } \\
\mathbf{E D}_{\mathbf{2 5}} \pm \mathbf{S E M}(\mathbf{m g} / \mathbf{k g})\end{array}$ & $\begin{array}{l}\text { After naltrexone } \\
\mathbf{E D}_{\mathbf{2 5}} \pm \mathbf{S E M}(\mathbf{m g} / \mathbf{k g})\end{array}$ & $\begin{array}{l}\text { Ratio } \\
\text { After/Pre }\end{array}$ \\
\hline Fentanyl & $0.077 \pm 0.01$ & $0.10 \pm 0.09^{*}$ & 1.29 \\
Morphine & $1.31 \pm 0.54$ & $2.55 \pm 0.51^{*}$ & 1.94 \\
Ibuprofen & $1.81 \pm 0.37$ & $3.75 \pm 1.27^{*}$ & 2.07 \\
Tramadol & $2.46 \pm 0.15$ & $5.36 \pm 1.37^{*}$ & 2.17 \\
Codeine & $11.85 \pm 0.90$ & $30.10 \pm 5.81^{*}$ & 2.54 \\
Meloxicam & $12.33 \pm 1.92$ & $35.84 \pm 2.52^{*}$ & 2.90 \\
Paracetamol & $35.40 \pm 3.92$ & $110.20 \pm 8.65^{*}$ & 3.11 \\
\hline
\end{tabular}




\section{Discussion}

The aim of the present study was to examine the nocifensive activity of NSAIDs and opioids in a model of moderate to severe pain, the tail flick assay and in addition the effect of naltrexone, a known MOR antagonist. The findings confirm the effect dose-dependent with specific potency of fentanyl, morphine, ibuprofen, tramadol, codeine, meloxicam and paracetamol. In greement with previous studies it was obtained a marked antinociception of NSAIDs and opioids in the tail flick assay [9 - 14]. However, the present findings do not agree with those reported by Zelcer et al., [15] that point out that NSAIDs are inactive in the tail flick trial. Furthermore, Kolesnikow et al [16] have reported that ibuprofen does not produce antinociception in the tail flick test. The difference between these results could be due to the species of animal used (rat versus mice), the doses administered ( $\mathrm{mg} / \mathrm{kg}$ versus ug / $\mathrm{kg}$ ), the routes of administration (i.t. versus i.p.), the assay used (visceral pain vs thermal pain).

The main finding of the present study was the inhibition of the antinociception through the antagonist MOR, naltrexone, on the antinociception induced by NSAIDs and opioids in the acute thermal assay of the tail flick. The results obtained with naltrexone in this assay confirm the antagonism of this agent on opioids [17-19]. However, the antagonism over NSAIDs is a new finding since that has not been previously reported.

NSAIDs are a heterogeneous group of drugs widely used for the treatment of pain. It is widely accepted that the main mechanism of action of these compounds, also involved for the side effect of gastric mucosal damage, is inhibition of cyclooxygenases (COXs), a key enzyme in prostanoids synthesis. The results obtained in this study demonstrate greater potency of COX-1 selective inhibitor NSAIDs (ibuprofen) than COX-2 selective (meloxicam) and both of greater potency than COX-3 associated inhibitors (paracetamol) [20]. COXs inhibition is not the only antinociceptive mechanism of action of NSAIDs. Additionally, preclinical studies have shown that there are other mechanisms that are involved in this antinociceptive effect, including their interaction with endocannabinoids CB1 and CB2, monoaminergic, and cholinergic systems. Interaction with nitric oxide (NO) through the inhibition of expression/activity of iNOS. Furthermore, antinociceptive effects of NSAIDs have been related with an endogenous opioid system possibly involving the descending pain modulatory circuit. Furthermore, NSAID-induced antinociception is also associated with decreased levels of dinorphins A in the frontal cortex and is prevented by blocking the $\kappa$-opioid receptors. Additionally, NSAIDs have been shown to have other alternative mechanisms for their antinociceptive function, among which are mentioned, down-regulation of L-selectin, inhibition of $\beta_{2}$ integrin activation, inhibition of NF-kappa $\beta$, modulation of IL-6, IL-1 $\beta$, matrix metalloproteinases, lactoferrin, phospholipase and others [3, 4, 10, 21 - 27].

In the present study the antinociceptive efficacy of fentanyl in the mouse tail flick assay was greater compared to morphine, tramadol or codeine. This finding agrees with previous work [28-29] and shows the higher potency of fentanyl. This finding confirms the functional selectivity [30-31] of fentanyl, an MOR agonist capable of producing antinociception and receptor regulation, in contrast to morphine, which by activating the same receptor, only produces antinociception. Furthermore, despite the fact that the opioids used are MOR agonists and antagonized by a MOR blocker (naltrexone), the difference in their activity could lie in the multiplicity of variants of the MOR-1 subtype, of which have been described around 20 in mice, with variable intrinsic activity and efficacy [15].

Opioids such as fentanyl, morphine, codeine, and tramadol are an important type of pain reliever and produce their effects by activating defined opioid receptors, although prolonged use induces serious side effects such as tolerance, dependence, and addiction. There are selective opioid receptor antagonists, including naloxone, naltrexone, naltrindole, and norbinaltorphimine that block the effects of opioids. In addition to activating the corresponding opioid receptors, there are alternative mechanisms that could help explain the antinociceptive activity of opioids. It has been reported that opioid receptor agonists induce antinociception by interaction through cannabinoid (CB1) receptors [8]. Also opioids activity have been reported by inhibition of both NA and 5-HT reuptake [24]. However, an important contribution to opioid antinociception is the interaction capacity to open $\mathrm{K}^{+}$channels and inhibit the opening of $\mathrm{Ca}^{+2}$ channels, ions that play a very important role in the transmission of the pain signal to through Substance P, neurokinin1, calcitonine gene related peptide, glutamate [28].

The administration of NSAIDs and opioids induced an antinociceptive effect, but with different potency, in the tail flick test. The mechanism of action of these drugs is different since one of them is related to the inhibition of COXs and the other to the activation of specific receptors. However, the antagonism produced by the MOR blocker, naltrexone, suggests that the inhibition of pain produced by these drugs is partially mediated by MOR and associated to central mechanisms.

This study provides new information related to the activity of antinociceptive drugs in a test that is highly correlated with the improvement of human pain. 


\section{Conclusion}

This study test that NSAIDs and opioids induce antinociceptive activity in a thermal murine phasic pain with the following rank orden of potency fentanyl $>$ morphine $>$ ibuprofen $>$ tramadol $>$ codeine $>$ meloxicam $>$ paracetamol. Although the mechanisms of action of these drugs are different, naltrexone, a MOR antagonist, blocked the effects of both agents, suggesting that inhibition of pain seem partially mediated by MOR with association to central mechanisms.

\section{Compliance with ethical standards}

\section{Disclosure of conflict of interest}

The authors declare no conflict of interest.

\section{Statement of ethical approval}

Experiments were performed in accordance with current Guidelines for The Care of Laboratory Animals and Ethical Guidelines for investigation of experimental pain approved by the Animal Care and Use Committee of the Faculty of Medicine, University of Chile, protocol CBA N $852 / 2018$.

\section{References}

[1] D'Amour FE and Smith DL. (1941).A method for determining loss of pain sensation. Journal of Pharmacology and Experimental Therapeutics 72,74-79.

[2] Millan MJ. (2002). Descending control of pain. Progress in Neurobiology, 66, 355-474.

[3] Hamza M and Dionne RA. (2009). Mechanism of non-opioid analgesics beyond cyclooxygenase enzyme inhibition. Current Molecular Pharmacology 2, 1-14.

[4] Diaz-Gonzalez F and Sanchez-Madrid F. (2015). NSAIDs, learning new tricks from old drugs. European Journal of Immunology, 45, 679-686.

[5] Gunaydin C and Sim Bilge SW. (2018) Effects of nonsteroidal anti-inflammatory drugs at the molecular level. European Jornal of Medicine 50, 116-121.

[6] Cox BM, Christie MJ, Devi L, Toll L and Traynor JR. (2015). Challenges for opioid receptor nomenclature, IUPHAR Review 9. British Journal of Pharmacology 172, 317-323.

[7] Granier S. (2012).Structure of mu and delta opioid receptors. Medicine Science (Paris) 28, 870-875.

[8] Dhaliwal A and Gupta M. (2020). Physiology, Opioid Receptor. StatPearls [Internet]. Treasure Island (FL), StatPearls Publishing.

[9] Miranda HF, Puig MM , Dursteler C, Prieto JC and Pinardi G. (2007).Dexketoprofen-induced antinociception in animal models of acute pain, Synergy with morphine and paracetamol. Neuropharmacology, 52, 291-296.

[10] Gorgiladze T, Nozadze I, Abzianidze E and Tsagareli M. (2017). Non- steroidal anti-inflammatory drugs's antinociception mediated by the opioid mechanism in the nucleus raphe magnus. News 265, 99-104.

[11] Miranda HF, Noriega V, Sierralta F, Poblete P, Aranda N and Prieto JC. (2019). Nitric oxide and opioids involvement in isobolographic NSAIDs antinociception. Drug Res (Stuttg) 69,688-694.

[12] Morgan MM, Reid RA, Stormann TM and Lautermilch NJ. (2014). Opioid selective antinociception following microinjection into the periaqueductal gray of the rat. Journal of Pain 15, 1102-1109.

[13] Dogrul A, Gülmez SE, Deveci MS, Gul H, Ossipov MH, Porreca F and Tulunay FC. (2007). The local antinociceptive actions of nonsteroidal anti-inflammatory drugs in the mouse radiant heat tail-flick test. Anesthesia \& Analgesia 104, 927-935.

[14] Miranda HF, Lopez J, Sierralta F, Correa and Pinardi G. (2001). NSAIDs antinociception measured in a chemical and a thermal assay in mice. Pain Research Management 6, 190-196.

[15] Zelcer S, Kolesnikov Y, Kovalyshyn I, Pasternak DA and Pasternak GW. (2005). Selective potentiation of opioid analgesia by nonsteroidal anti- $\quad$ inflammatory drugs. Brain Research, 1040, 151-156. 
[16] Kolesnikov YA, Wilson RS and Pasternak GW. (2003). The synergistic analgesic interactions between hydrocodone and ibuprofen. Anesthesia \& Analgesia, 97, 1721-1723.

[17] Miczek KA and Winslow JT. (1987). Analgesia and decrement in operant performance in socially defeated mice, selective cross-tolerance to morphine and antagonism by naltrexone.Psychopharmacology, 92, 444-451.

[18] Carr DJ, Gerak LR and France CP. (1994). Naltrexone antagonizes the analgesic and immunosuppressive effects of morphine in mice. Journal of Pharmacology and Experimental Therapeutics, 269, 693-698.

[19] Miranda HF, Noriega V, Zanetta P, Prieto JC, Prieto-Rayo JC, Aranda N and Sierralta F. (2014). Isobolographic analysis of the opioid-opioid interactions in a tonic and a phasic mouse model of induced nociceptive pain. Journal of Biomedical Science, 21, 62-70.

[20] Brune K and Patrignani P. (2015). New insights into the use of currently available non-steroidal anti-inflammatory drugs. Journal of Pain Research, 8, 105 - 118.

[21] Dani M, Guindon J, Lambert C and Beaulieu P. (2007). The local antinociceptive effects of paracetamol in neuropathic pain are mediated by cannabinoid receptors. European Journal of Pharmacology, 573, $214-215$.

[22] Ottani A, Leone S, Sandrini M, Ferrari A and Bertolini A. (2006). The analgesic activity of paracetamol is prevented by the blockade of cannabinoid CB1 receptors. European Journal of Pharmacology, 531, 280-281.

[23] Dudhgaonkar SP, Tandan SK, Kumar D, Arunadevi R and Prakash VR. (2008). Synergistic interaction between meloxicam and aminoguanidinein formalin-induced nociception in mice. European Jounal of Pain 12, 321328.

[24] Bravo L, Llorca-Torralba M, Berrocoso E and Micó JA. (2019). Monoamines as Drug Targets in Chronic Pain, Focusing on Neuropathic Pain. Frontiers in Neuroscience, 13, - 1293.

[25] Alloui A, Chassaing C, Schmidt J, Ardid D, Dubray C, Cloarec A and Eschalier A. (2002). Paracetamol exerts a spinal, tropisetron-reversible, antinociceptive effect in an inflammatory pain model in rats. European Journal of Pharmacology ,443, 71-77.

[26] Sandrini M, Romualdi P, Vitale G, Morelli G, Capobianco A, Pini LA and Candeletti S. (2001). The effect of a paracetamol and morphine combination on dynorphin A levels in the rat brain. Biochemical Pharmacology 61, 1409-1416.

[27] Dwivedi AK, Gurjar V, Kumar S and Singh N. (2015). Molecular basis for nonspecificity of nonsteroidal antiinflammatory drugs (NSAIDs). Drug Discovery , 20, 863-873.

[28] Adams JU, Paronis CA and Holtzman SG. (1990). Assessment of relative intrinsic activity of mu-opioid analgesics in vivo using beta-funaltrexamine. Journal of Pharmacology and Experimental Therapeutics 255, 1027-1032.

[29] Sirohi S, Dighe SV, Walker EA and Yoburn BC. (2008). The analgesic efficacy of fentanyl, relation to tolerance and $\mu$-opioid receptor regulation. Pharmacology, Biochemistry and Behavior, 91, 115- 120.

[30] Mailman RB. (2007). GPCR functional selectivity has therapeutic impact. Trend Pharmacologial Science 28, 390396.

[31] Fornasari D and Coaccioli S. (2014). Pharmacology of pain. Reumatismo, 66, 14-17.

\section{How to cite this article}

Miranda HF, Noriega V, Sierralta F, Sotomayor-Zárate R and Prieto JC. (2020). NSAIDs and opioids antinociception in a thermal murine phasic pain. GSC Advanced Research and Reviews, 2(3), 64-70. 